\title{
Gains from Specialization and Free Agency: The Story from the Gridiron
}

\author{
Rob Simmons • David J. Berri
}

Published online: 7 February 2009

(C) Springer Science+Business Media, LLC. 2009

\begin{abstract}
In the field of personnel economics, there are few opportunities to convincingly test for salary returns to specialization as against versatility. This paper performs such a test by modeling returns to performance measures associated with two different skills practiced by running backs in the National Football League. We find gains to both specialization and free agency with substantial predicted differences in returns for alternative skills. These differences vary across the salary distribution. In the top half of the salary distribution, model simulations show that specialists in either particular skill generate higher marginal returns than do versatile players.
\end{abstract}

Keywords Free agency $\cdot$ National Football League $\cdot$ Salary $\cdot$ Specialization

\section{Introduction}

Two of the most fundamental principles of economics, taught in ECON 101 classes worldwide, are diminishing marginal returns to labor in production and the gains, to both workers and employers, from specialization. The advantages of specialization and division of labor were highlighted in Adam Smith's celebrated example of the pin factory, with the important caveat that the level of specialization is limited 'by the extent of the market' (Stigler 1951). These principles seem to be well-suited to manufacturing plants with production line technology where workers perform welldefined, specific tasks. In this environment, workers generate increased productivity,

\footnotetext{
R. Simmons $(\varangle)$

Department of Economics, Lancaster University, Lancaster LA1 4YX, UK

e-mail: r.simmons@lancaster.ac.uk

D. J. Berri

Department of Economics, Southern Utah University, Cedar City, UT, USA
} 
and higher pay in a competitive labor market, through experience and learning by doing in their chosen specialized tasks.

In contrast to this picture of specific job tasks, a recent literature has pointed to the importance of multi-skilling and multi-task production activity in which workers are rewarded for their versatility and potential to offer synergies rather than for specialization (Black and Lynch 2004). This literature points to the influence of Japanese firms in pioneering new human resource management policies that emphasize features of cooperation and teamwork with interchangeable processing of tasks (Carmichael and MacLeod 1993; Baron and Kreps 1999). One reading of the evolution of human resource management over the last 25 years is that North American and European firms imitated the 'new' human resource management policies of Japanese firms, in order to compete in increasingly global markets.

Despite the emergence of multiskilling and multitasking, professional occupations continue to be specialized. Lawyers tend to be highly specialized, and production of their services is often hierarchically organized (Garicano and Hubbard 2007). Doctors continue to specialize in particular surgical procedures, and economists do research in sub-fields of the discipline. Within households, there is some evidence of a significant wage premium to marriage associated with intra-household specialization in household production (Bardasi and Taylor 2008).

Empirical identification of multi-skilling or specialization in economic activities is extremely difficult, particularly where questionnaire surveys of managers or workers are being used (Green et al. 1998). The limitations of broad questionnaire surveys, with subjective and possibly unreliable responses, represent one good reason why some economists have recently focused on in-depth analysis of the effects of human resource management policies in particular manufacturing plants. This approach, called 'nanoeconometrics' from the pioneering contribution of Ichniowski and Shaw (2003) on U.S. steel plants, allows economists to obtain precise measures of worker performance and rewards.

The present paper is an example of nano-econometrics, using the sports industry as our setting. Kahn's (2000) description of the team sports industry as a labor market laboratory is apposite here. Each of the major North American team sports offers detailed and widely available (i.e., not proprietary) data on job tasks (positions within teams), career records, player and team performance, and player salaries. In each major sport there is a plethora of on-line information that tracks player performances over many years.

In American football, organized in the National Football League (henceforth, NFL), players have well-defined roles within games. Most plays are designed, at least partly, by the team's coaches and set down in team playbooks. These designs set forth the assignment for each player on the field of play.

Although on a given play a player's role is set, in the course of a game roles can vary. To illustrate, consider the activities of running backs: These players have three main functions: to run with the ball (rushing), to catch passes thrown by the quarterback (pass receptions), and to block opponents to help teammates run with the ball or catch passes. The general aim of these functions is to make forward progress downfield by gaining yards in sets of four 'downs'. By making downfield progress, the team's offense aims to score points by a variety of methods, of which the most common are 
touchdowns, achieved by moving the ball past the opposing team's goal line, or field goals, scored by kicking the ball between the posts of the goal.

Over the history of the NFL, the best running backs have combined the rushing and pass reception functions in different ways. Barry Sanders retired from the NFL in 1998, ending a Hall-of-Fame career. In ten years Sanders rushed for 15,269 yards, a total eclipsed only by Walter Payton and Emmitt Smith. When we consider the 2,921 yards Sanders had receiving passes, we see that he averaged 119 yards from scrimmage per game in his career. Per game the performance of Sanders eclipsed both Payton and Smith, with Payton averaging 112 yards from scrimmage per game, while Smith only averaged 95.5 yards.

Our interest in running backs is not so much how many yards the players accumulated, but how the yards were gained. If we look at each of these backs, we see that yards from scrimmage were primarily gained via rushing. For Payton, 79\% of his total yards gained from scrimmage were accumulated via rushing, not catching passes out of the backfield. Sanders and Smith posted career percentages of $84 \%$ and $85 \%$, respectively.

In contrast, Marshall Faulk proved to be a somewhat different kind of running back: In Faulk's twelve-year career he gained 19,154 yards from scrimmage, a total that surpasses Sanders and rivals the career output of Smith and Payton. Relative to these other backs, though, Faulk was far less of a specialist. Only 64\% of Faulk's yards from scrimmage came from rushing. While Sanders, Smith, and Payton averaged fewer than 25 yards receiving per game, Faulk averaged close to 40 yards. In essence, Sanders, Smith, and Payton were specialists, while Faulk attempted to excel at both aspects of a team's offensive attack.

The differences in how running backs gain yards motivates our inquiry. Is it better for a running back to specialize? Or does the NFL reward versatility? The context for analysis of these questions is a player labor market with two key features that generate monopsony power for team owners. First, there are only 32 teams in the NFL, and there is no rival league of comparable quality. Second, the majority of players enter the NFL via a system of player draft from colleges. Teams then have exclusive rights to player services over a four-year period. Our sample of players contains some who are free agents and some who are tied to their teams via a reserve clause. This will allow us to estimate the salary returns to becoming a free agent. ${ }^{1}$

The answers to our questions will be organized as follows: First, in section II, we examine the value of rushing and passing to a team's offensive performance. This discussion will be followed in section III by an empirical examination of salaries of running backs in the NFL. Do the people who are supposed to know best, the front office human resource managers in NFL franchises, pay for specialization or versatility? Our empirical results are reported in section IV. A concluding section V will summarize our findings.

\footnotetext{
${ }^{1}$ Even with free agency, bidding is not competitive. Given only 32 teams and a barrier to entry that is not legally threatened, players actually face an oligopsonistic labor market for their services. The literature on monopsony power in team sports has focused on Major League Baseball (Scully 1974; Medoff 1976; Raimondo 1983; Krautmann 1999). The consensus from the literature is that player salaries rose substantially after the introduction of free agency in baseball in 1976, and that this is associated with a reduction in monopsony power.
} 


\section{A Balanced Attack}

The first step in our analysis is to examine the effects that rushing and passing have on a team's offense. Our methodology follows from the work of Berri et al. (2006) and Berri (2007).

Each of these works presented a model of offensive performance in the NFL. The dependent variable, offensive point production (OFFPTS), is the number of points a team scores that can be attributed to a team's offense. ${ }^{2}$ This factor is then regressed on the collection of independent variables listed in Table 1 and in equation (1).

$$
\begin{aligned}
& \text { OFFPTS }=\mathrm{a}_{\mathrm{ik}}+\mathrm{a}_{1} * \text { DKO }+\mathrm{a}_{2} * \text { DPUNTS }+\mathrm{a}_{3} * \text { DFGMISS }+\mathrm{a}_{4} * \text { DINT } \\
& (+) \quad(+) \quad(+) \quad(+) \\
& +\mathrm{a}_{5} * \text { DFUMLST }+\mathrm{a}_{6} * \text { START }+\mathrm{a}_{7} * \text { OFFYDS }+\mathrm{a}_{8} * \text { PENYDS } \\
& (+) \quad(-) \quad(+) \quad(+) \\
& +\mathrm{a}_{9} * \underset{(-)}{\operatorname{DPENYDS}}+\mathrm{a}_{10} * \underset{(-)}{\operatorname{PLAYS}}+\mathrm{a}_{11} * \underset{(+)}{3 \mathrm{RDCON}}+\mathrm{a}_{12} * \underset{(-)}{\operatorname{FGMISS}} \\
& +\mathrm{a}_{13} * \mathrm{INT}_{(-)}+\mathrm{a}_{14} * \underset{(-)}{\mathrm{FUMLST}}+\mathrm{a}_{15} * \underset{(+)}{\mathrm{TDRATE}}+\mathrm{a}_{16} * \underset{(-)}{\mathrm{XPCON}}
\end{aligned}
$$

Table 1 separates the independent variables into four separate actions: Acquisition of the Ball, Moving the Ball, Maintaining Possession, and Scoring. Of the sixteen independent variables that comprise these actions, we are most interested in Total Offensive Yards Gained (OFFYDS). This factor, listed under Moving the Ball, is calculated by adding rushing (RUSHYDS) and passing yards (PASSYDS) together. Descriptive statistics for all the variables in equation (1) are shown in Table 2. Definitions and sources of our data are shown below in the Data Appendix.

It is possible that rushing and passing yards have differing effects on scoring, and before we discuss the economic returns to these actions the value of rushing and receiving on the field has to be ascertained. Consequently equation (1) was estimated with OFFYDS separated into RUSHYDS and PASSYDS. The results are reported in Table 3. Parameter estimates of all independent variables have the expected signs.

Berri (2007) reported that each additional OFFYDS increased scoring by 0.08 , or 100 additional yards would lead to 7.96 additional points. From Table 3 we see that each additional RUSHYDS and PASSYDS also lead to 0.08 points. When we compare 100 RUSHYDS to 100 PASSYDS, we see that the former generates 8.30 points while the latter creates 7.85 points.

Although the coefficients on RUSHYDS and PASSYDS are virtually the same, a case can still be made for the proposition that the returns to receiving are higher than the returns to rushing. In order to acquire yards a running back must expend a Play. Table 3 indicates that each Play, holding all else constant, costs a team -0.021

\footnotetext{
2 This is calculated by first noting that a team's offense can score via touchdowns from its rushing attack or its passing game. For each touchdown a team has the opportunity to score either one or two extra points. If a team fails to score a touchdown, a team can also score points via field goals. The NFL does not record how many extra points are derived from offensive touchdowns and how many come from touchdowns generated by a team's special teams or defense. To estimate the number of extra points from offensive touchdowns one can look at the percentage of touchdowns scored by the team's offense. One then simply assumes that this percentage represents the percentage of extra points scored by the team's offense.
} 
Table 1 Factors affecting a team's offensive ability

\begin{tabular}{ll}
\hline Actions & Variables tabulated \\
\hline Acquisition of the ball & Opponent's kick-offs (DKO) \\
& Opponent's punts (DPUNTS) \\
& Opponent's missed field goals (DFGMISS) \\
& Opponent's interceptions (DINT) \\
Opponent's fumbles lost (DFUMLST) & Average starting position of drives (START) \\
Total offensive yards gained $=$ OFFYDS = RUSHYDS + PASSYDS \\
Total rushing yards gained (RUSHYDS) \\
Total passing yards gained (PASSYDS) \\
Total penalty yards lost (PENYDS) \\
Total penalty yards lost by the opponent (DPENYDS) \\
PLAYS = RUSHATT + PASSATT + SACKED \\
Rushing attempts (RUSHATT) \\
Passing attempts (PASSATT) \\
Sacks (SACKED) \\
Third down conversion rate (3RDCON) \\
Missed field goals (FGMISS) \\
Interceptions (INT) \\
Fumbles lost (FUMLOST) \\
Touchdown rate = TDRATE = OFFTD / (OFFTD + FGMADE) \\
Touchdowns scored by a team's offence (OFFTD) \\
Field goals made (FGMADE) \\
Extra points conversion rate = XPRATE = OFFXP / OFFTD \\
Extra points earned on offensive touchdowns (OFFXP) \\
\hline Scoring
\end{tabular}

points. Looking at a sample of running backs that had at least 100 rushing attempts in a season from 1994 to 2006, we can see that the average back gains 4.08 yards per rushing attempt but 7.93 yards per reception. ${ }^{3}$ Given these averages, to gain 100 yards rushing an average back would have to rush 24.5 times, at a cost of 5.17 points. To gain 100 yards receiving, though, would only require 12.61 receptions at a cost of 2.66 points. When we add together the points from yards gained to the cost of the plays, we see that 100 rushing yards produce 3.13 points while 100 yards receiving generate 5.19 points. Hence, team returns to pass reception yards are greater than team returns to rush yards. ${ }^{4}$ This raises the question of the extent to which these differences in effects of passing and rushing yards translate into similar differences in player compensation. If compensation reflects player marginal physical product, then players who generate an additional number of extra passing yards will be expected to earn higher salaries than players who generate the same extra rushing yards, ceteris paribus.

\footnotetext{
3 Note that it is a convention in NFL statistics for incomplete passes to be placed in the quarterback category rather than counted against receivers. Although dropped passes are observed (but not recorded in archived data), it is difficult to assign responsibility for a missed reception when the ball passes over or by a receiver. There is no straightforward mechanism available in existing data sources to correct average yards gained by a running back by a pass incompletion rate.

4 We should note that the benefits to rushing extend beyond the yardage gained per play. It is generally believed that running the ball can wear a defense down, making it easier to gain yardage in the fourth quarter. We thank an anonymous referee for making this observation.
} 
Table 2 Descriptive statistics for continuous variables

\begin{tabular}{|c|c|c|c|c|c|c|}
\hline Variable & Label & Mean & Median & Maximum & Minimum & $\begin{array}{l}\text { Standard } \\
\text { deviation }\end{array}$ \\
\hline \multicolumn{7}{|l|}{ Offensive Points Model } \\
\hline Offensive Points & OFFPTS & 308.59 & 303.00 & 512.00 & 154.00 & 67.63 \\
\hline Opponent's Kick-offs & DKO & 77.31 & 77.00 & 103.00 & 48.00 & 9.74 \\
\hline Opponent's Punts & DPUNTS & 79.61 & 79.00 & 115.00 & 50.00 & 10.78 \\
\hline $\begin{array}{l}\text { Opponent's } \\
\text { Missed Field } \\
\text { Goals }\end{array}$ & DFGMISS & 6.26 & 6.00 & 14.00 & 0.00 & 2.55 \\
\hline $\begin{array}{l}\text { Opponent's } \\
\text { Interceptions } \\
\text { Thrown }\end{array}$ & DINT & 16.91 & 16.00 & 33.00 & 5.00 & 5.25 \\
\hline Opponent's Fumbles Lost & DFUMLST & 12.22 & 12.00 & 26.00 & 5.00 & 3.81 \\
\hline $\begin{array}{l}\text { Average Starting } \\
\text { Position of Drives }\end{array}$ & START & 31.16 & 31.28 & 36.47 & 26.17 & 1.79 \\
\hline Yards Gained, Rushing & RUSHYDS & $1,813.85$ & $1,777.00$ & $2,774.00$ & $1,062.00$ & 335.86 \\
\hline Yards Gained, Passing & PASSYDS & $3,313.21$ & $3,314.00$ & $5,232.00$ & $1,898.00$ & 552.82 \\
\hline Penalty Yards & PENYDS & 876.03 & 883.00 & $1,304.00$ & 481.00 & 140.55 \\
\hline Opponent's Penalty Yards & DPENYDS & 876.03 & 874.00 & $1,292.00$ & 535.00 & 121.89 \\
\hline Plays & PLAYS & $1,007.00$ & $1,012.00$ & $1,118.00$ & 859.00 & 45.76 \\
\hline Third Down Conversion Rate & $3 \mathrm{RDCON}$ & 37.77 & 37.69 & 52.31 & 24.00 & 5.14 \\
\hline Field Goals Missed & FGMISS & 6.26 & 6.00 & 15.00 & 0.00 & 2.56 \\
\hline Interceptions Thrown & INT & 16.91 & 16.00 & 34.00 & 6.00 & 4.69 \\
\hline Fumbles Lost & FUMLST & 12.23 & 12.00 & 22.00 & 2.00 & 3.80 \\
\hline $\begin{array}{l}\text { Percentage of Scores that } \\
\text { are Touchdowns }\end{array}$ & TDRATE & 0.59 & 0.59 & 0.78 & 0.35 & 0.08 \\
\hline $\begin{array}{l}\text { Extra Point Conversion Rate } \\
\text { Salary Model }\end{array}$ & XPCON & 0.97 & 0.98 & 1.12 & 0.75 & 0.06 \\
\hline Salary & & $1,044,211$ & 590,000 & $15,000,000$ & 52,941 & $1,288,310$ \\
\hline Real salary & & $1,009,395$ & 578,086 & $13,200,000$ & 37,883 & $1,145,553$ \\
\hline Experience & & 5.07 & 4.00 & 16 & 1 & 2.75 \\
\hline Offensive line salary (nominal) & & $10,300,000$ & $9,304,100$ & $32,900,000$ & $1,852,272$ & $4,296,813$ \\
\hline Offensive line salary (real) & & $9,896,107$ & $9,990,046$ & $19,900,000$ & $1,395,835$ & $2,851,238$ \\
\hline Population & & $4,090,067$ & $2,855,711$ & $18,800,000$ & 262,056 & $4,051,919$ \\
\hline Career rush yards & & 1,259 & 311 & 17,216 & -1 & 2,259 \\
\hline Career receiving yards & & 558 & 192 & 6,584 & -2 & 925 \\
\hline Rush yards & & 363 & 161 & 2,066 & -5 & 445 \\
\hline Receiving yards & & 156 & 102 & 1,387 & -3 & 171 \\
\hline
\end{tabular}

\section{Economic Returns to Receiving and Running}

Based on our model of scoring, the yards that a running back gains via rushing or receiving do appear to have somewhat different impacts on the field of play. Are these yards treated differently in the marketplace? To answer this question we turn to a model of player salaries.

The model of player salaries used here follows the generic Mincer form in the sports literature where player salary is assumed to depend on experience, player performance, and team characteristics. This model has been used by see Scully (1974) and Krautmann (1999) for baseball, Bodvarsson and Partridge (2001); Hamilton (1997), and Kahn and Shah (2005) for basketball, Kahn (1992) for the NFL, 
Table 3 Modeling offensive scoring dependent variable: Offensive Points Scored (OFFPTS). Team fixed effects and dummy variables for each season are employed

\begin{tabular}{llrr}
\hline Variable & Label & Coefficient & t-Statistic \\
\hline Opponent's Kick-offs & DKO* & 0.93 & 3.67 \\
Opponent's Punts & DPUNTS** & 0.43 & 2.12 \\
Opponent's Missed Field Goals & DFGMISS & 0.48 & 0.82 \\
Opponent's Interceptions Thrown & DINT* & 1.26 & 4.28 \\
Opponent's Fumbles Lost & DFUMLST** & 1.01 & 2.49 \\
Average Starting Position of Drives & START* & 10.03 & 11.17 \\
Yards Gained, Rushing & RUSHYDS* & 0.08 & 13.46 \\
Yards Gained, Passing & PASSYDS* & 0.08 & 17.98 \\
Penalty Yards & PENYDS & -0.01 & -1.21 \\
Opponent's Penalty Yards & DPENYDS* & 0.06 & 5.02 \\
Plays & PLAYS* & -4.12 \\
Third Down Conversion Rate & 3RDCON* & 1.91 & 3.93 \\
Field Goals Missed & FGMISS* & -3.00 & -5.35 \\
Interceptions Thrown & INT* & -1.29 & -3.49 \\
Fumbles Lost & FUMLST* & -1.49 & -3.56 \\
Percentage of Scores that are Touchdowns & TDRATE* & 101.56 & 4.46 \\
Extra Point Conversion Rate & XPCON & 44.07 & 1.58 \\
Adjusted R-squared & 0.910 & & \\
Observations & 251 & & \\
\hline
\end{tabular}

Note: Dependent Variable: Offensive Points Scored (OFFPTS). Team Fixed Effects and Dummy Variables for each season are employed. The data utilized to estimate this model came from various issues of the Official National Football League Record \& Fact Book. The lone exception is START, which was taken from Football Outsiders.com

* Significance at the $1 \%$ level

** Significance at the $5 \%$ level

Idson and Kahane (2000) for hockey, and Lucifora and Simmons (2003) for Italian soccer.

Our dependent variable is log real player salary. Basic salary levels are set within a pay scale determined by the collective bargaining agreement between the players' association (NFLPA) and team owners. ${ }^{5}$ The pay scales will reflect player experience in the NFL. Signing bonuses are determined through bilateral bargaining between team owners and the player without union involvement. In any season, it follows that the variation in signing bonuses will be somewhat larger than the variation in basic salaries. Over our sample period, an increasing share of total player salary appears to be accounted for by signing bonuses. For the purposes of salary cap computation, any signing bonuses are pro-rated over the life of the player's contract.

Salary distributions in most occupations are not log-normal; and in team sports skewness in the distribution is particularly marked, with a few top players earning

\footnotetext{
5 The NFL operates a salary cap that specifies an upper limit to the ratio of team payroll to gross designated revenues. The salary cap does not specify any limit on individual salaries; hence, it is more accurate to refer to this as a cap on payroll. Moreover, the cap can be partly circumvented as some revenues (such as revenues from leasing luxury boxes at stadia) do not count against the cap. Nevertheless, the distribution of team payrolls in NFL is more compressed than in other North American sports, and the salary cap can be viewed as binding.
} 
substantially more than their colleagues (Garicano and Hubbard 2007; Lucifora and Simmons 2003). Non-normality and excess kurtosis in the dependent variable may result in variations of marginal returns to particular characteristics throughout the salary distribution (Leeds and Kowalewski 2001). For our sample of 1,425 player-seasons we find a kurtosis value of 3.24. Since this value exceeds 3, we have excess kurtosis, and we are reluctant to proceed with ordinary least squares estimation for our model. ${ }^{6}$

Following earlier contributions on player salaries by Hamilton (1997) and Leeds and Kowalewski (2001), we adopt the quantile regression method for estimation. ${ }^{7}$ At the median, quantile regression differs from ordinary least squares in that it minimizes the sum of absolute residuals rather than the sum of squared residuals (Koenker 2005). A strong advantage of quantile regression is that it permits estimation of marginal effects of covariates at different points of the distribution of the dependent variable. In our case, we can estimate the impacts of player performance measures on log salary at different salary quantiles.

Our list of independent variables begins with Experience. As with the human capital model, we expect NFL experience to affect players' salaries positively ${ }^{8}$ but with diminishing returns to reflect the wear and tear on the body and decline in physical ability (speed and strength) that is clearly apparent in playing careers that average just four years in this highly physical sport. Diminishing returns to experience are captured by a quadratic form with the addition of Experience squared.

NFL experience for most players is preceded by the league's player draft. There are 12 draft rounds, and players drafted in earlier rounds tend to be of higher quality than players drafted in later rounds. Hence, earlier round choices should have greater salaries. Also, players selected in earlier rounds will receive greater technical and coaching support than do players selected in later rounds, so the prediction that these players will earn larger salaries is partly self-fulfilling.

We should note that the draft is an imperfect predictor of playing talent, especially as teams use the draft partly as a trading exchange for players (Hendricks et al. 2003; Quinn 2006). ${ }^{9}$ We adopt Draft round 1 and Draft round 2 as dummy variables to reflect draft choices. We assume that once achieved, high draft status remains an influence on player salary throughout the player's career.

\footnotetext{
${ }^{6}$ If salaries are deflated by CPI, rather than average NFL wage, the kurtosis value becomes 3.84 , suggesting an even stronger departure from log-normality in the dependent variable.

7 The deflation of salaries by average NFL wage rather than by CPI now becomes pertinent. If salaries are deflated by CPI, then players can move between quantiles purely by salary inflation, as opposed to sustained performance. Instead, scaling by average NFL salary in a particular season means that we can compare players at a given quantile that are several seasons apart.

${ }^{8}$ In the human capital model of pay determination, workers raise their marginal revenue products through increased work experience, which is associated with learning by doing. In the NFL, players do learn from on-field playing experience, but the experience is itself a direct reflection of ability as team coaches will select what they regard as the best players to appear in games and particular plays. So experience in the NFL is largely a function of successful selection; and in training camps and in practice sessions, what is classified as 'training' is actually an elaborate selection process that is designed to identify appropriate players for upcoming games.

${ }^{9}$ It is common for a player to be traded in the current season in exchange for one or more draft picks of the buying team in future seasons.
} 
Players with three years experience in the NFL are entitled to 'restricted free agency'. After three years, a player can seek contract offers from rival teams, but the current team is entitled to present a matching offer. Such players are denoted by the dummy variable, Restricted free agent.

NFL players are entitled to unfettered free agency status after four seasons' playing experience. Players who have at least four years' experience are denoted by the dummy variable Veteran. Several players remained with their drafting team even though they had acquired free agent status. This is presumably because the drafting team offered the player a contract with a valuation at least as high as any alternative offer by another team in the market for free agents. Such players who remain with their original drafting teams despite being free agents are denoted by the dummy variable Stayer. This is set at one until the player switches teams. We predict that both 'veterans' and 'stayers' will earn higher salaries than do players who do not have free agent status (see Krautmann et al. 2007 for a full account of conditions for free agency in NFL).

Inspection of our data suggests that players often receive a lower salary when they change teams. We capture this effect by a dummy variable, Change team, where the value of unity only applies for the first season in which a player represents a different club. This variable was found to be negative and significant in the analysis of NFL quarterback salaries of Berri and Simmons (2009). Their rationale was that teams that identified an effective job match with their quarterbacks would offer salaries in excess of outside opportunities, even for free agents. Players who switch teams would then tend to be those deemed surplus to requirements. We anticipate a similar effect for running backs.

A useful proxy for peer esteem is appearance in the annual Pro Bowl exhibition game (Pro bowl). We expect that running backs who had at any time previously appeared in the Pro Bowl will receive higher salaries ceteris paribus.

As noted above, modeling complementarity of player inputs is still in its infancy in the sports economics literature (Borland 2006). Players on the interior offensive line do not have identifiable (to the econometrician) measures of performance, yet their efforts are important for team success. These players block defensive players in an effort to give skill players the time and space necessary to move the ball. We can proxy the quality of the offensive line by noting the total salary of this unit on the team. ${ }^{10}$ In a competitive labor market, offensive line payroll would be an extremely good proxy for the overall quality of the offensive line. However, the NFL labor market contains monopsonistic features. Players who are not free agents tend to receive salaries below marginal revenue product (Krautmann et al. 2007), and as a result the relationship between team performance and team payrolls is expected to be weak. ${ }^{11}$ Consequently, the relationship between payroll and latent performance of the offensive line is bound to be imperfect. Despite the problems associated with our measure, we expect a better (more expensive) offensive line should present running backs with improved opportunities to gain yards and should hence raise their productivity and salaries. We use the log of offensive line salary, to include all interior offensive line

\footnotetext{
10 For simplicity, our measure covers interior linemen only and excludes tight ends, who have dual roles in both blocking and receiving passes.

11 As was shown by Simmons and Forrest (2004).
} 
players on a team's roster in a given season. We predict complementarity between interior offensive line and running backs in team production and hence a positive coefficient on offensive line salary.

We retain one further team characteristic: market size. This is proxied by the log of SMSA population (Population). It might be argued that teams in larger markets (New York Giants and Jets) can afford to pay higher salaries than can teams in smaller markets (Kansas City Chiefs and Green Bay Packers). The NFL does have a binding salary cap that is designed to prevent this outcome. This cap is reinforced by extensive revenue sharing of both gate and broadcast revenues. If effective, these measures should serve to reduce the impact of market size on team revenues and hence on individual pay.

There are some running backs — called fullbacks — that have blocking as their primary function. These backs typically perform relatively little ball carrying or pass receiving and are generally taller and heavier than other running backs. We create a dummy variable, fullback, for these players.

Turning to our performance measures, we predict that players with established career performance will be rewarded with higher salaries than those who lack sustained performance. We include career rushing yards (Career rush yards) and total career pass reception yards (Career receiving yards) up to and including two seasons before the time that the player's salary was determined.

Since total salary is determined before the season in question, we expect that performance measures from the previous season to be significant determinants of current salary. We include Rush yards and Receiving yards as our key performance metrics for running backs. We are not simply interested in the returns to rushing and receiving. Our test for specialization of running backs uses the interaction term Receiving yards * Rush yards. The sign of the coefficient on this term offers insight into whether or not specialization raises running back salary. If pass reception yards and rush yards are complements in salary determination, we would predict the coefficient on the interaction term to be positive. This would suggest salary gains from versatility. A negative coefficient suggests that an increase in one measure of player performance reduces the marginal salary returns of the other measure. Hence, an increase in pass reception yards may reduce the marginal returns to rush yards and vice versa. The implication is that running backs would be better off in salary from specialization in either pass receptions or rushing.

Table 2 reports descriptive statistics for continuous measures of salary, experience, and performance. To summarize, our salary model is:

Log salary $=F($ Experience, Experience squared, Draft round 1, Draft round 2, Veteran, Stayer, Restricted free agent, Change team, Offensive line salary, Offense salary, Pro Bowl, Population, Fullback, Career rush yards, Career receiving yards, Rush yards, Receiving yards, Receiving yards* Rush yards)

The selected quantiles for estimation are 0.1, 0.25, 0.5 (median), 0.75, and 0.9. Quantiles are estimated with bootstrapped standard errors, to correct for heteroskedasticity. $^{12}$

\footnotetext{
12 Estimation is via the bsqreg command in Stata 10.0.
} 
Table 4 Quantile salary regression results

\begin{tabular}{|c|c|c|c|c|c|}
\hline Variable & 0.10 & 0.25 & 0.50 & 0.75 & 0.90 \\
\hline Experience & $0.254(3.88)$ & $0.240(5.20)$ & $0.218(5.36)$ & $0.170(3.51)$ & $0.211(3.40)$ \\
\hline Experience squared & $-0.020(4.23)$ & $-0.017(6.17)$ & $-0.016(5.89)$ & $-0.014(4.67)$ & $-0.016(4.12)$ \\
\hline Draft round 1 & $0.576(6.64)$ & $0.525(5.77)$ & $0.588(7.32)$ & $0.645(9.05)$ & $0.708(7.80)$ \\
\hline Draft round 2 & $0.262(3.18)$ & $0.282(5.16)$ & $0.262(6.23)$ & $0.252(6.22)$ & $0.236(3.47)$ \\
\hline Veteran & $0.106(0.80)$ & $0.067(0.61)$ & $0.170(2.13)$ & $0.312(3.42)$ & $0.310(2.26)$ \\
\hline Stayer & $0.110(1.56)$ & $0.186(3.17)$ & $0.212(4.08)$ & $0.182(2.92)$ & $0.300(3.60)$ \\
\hline Restricted free agent & $0.097(1.01)$ & $0.161(2.51)$ & $0.181(3.47)$ & $0.243(3.67)$ & $0.301(3.03)$ \\
\hline Change team & $-0.721(5.57)$ & $-0.442(7.00)$ & $-0.284(7.33)$ & $-0.240(4.75)$ & $-0.167(2.45)$ \\
\hline Offensive line salary & $0.168(1.91)$ & $0.180(3.91)$ & $0.205(4.53)$ & $0.150(3.12)$ & $0.163(2.29)$ \\
\hline Pro bowl & $0.257(3.56)$ & $0.237(3.53)$ & $0.294(4.67)$ & $0.419(5.27)$ & $0.370(4.08)$ \\
\hline Population & $-0.019(0.80)$ & $-0.005(0.29)$ & $-0.006(0.33)$ & $-0.012(0.67)$ & $-0.010(0.43)$ \\
\hline Fullback & $0.127(2.54)$ & $0.076(2.40)$ & $0.094(2.85)$ & $0.074(2.22)$ & $-0.002(0.03)$ \\
\hline Career rush yards & $0.065(3.00)$ & $0.030(1.92)$ & $0.032(1.93)$ & $0.030(2.08)$ & $0.046(2.16)$ \\
\hline Career receiving yards & $0.097(1.72)$ & $0.122(3.86)$ & $0.086(2.08)$ & $0.059(1.53)$ & $0.014(0.31)$ \\
\hline Rush yards & $0.040(3.91)$ & $0.056(7.08)$ & $0.066(7.92)$ & $0.075(8.90)$ & $0.084(6.57)$ \\
\hline Receiving yards & $0.087(5.12)$ & $0.061(4.79)$ & $0.080(5.27)$ & $0.125(6.50)$ & $0.138(4.83)$ \\
\hline Receiving yards * Rush yards & $-0.053(1.97)$ & $-0.037(1.83)$ & $-0.046(2.06)$ & $-0.085(3.59)$ & $-0.107(3.18)$ \\
\hline Pseudo $\mathrm{R}^{2}$ & 0.350 & 0.406 & 0.473 & 0.521 & 0.514 \\
\hline
\end{tabular}

Note: Dependent variable is log real salary for running backs with positive plays in previous season; sample period 1995-2006; $\mathrm{N}=1425$. The t-statistics are computed using bootstrapped standard errors with 200 replications

\section{Results}

The estimation of our salary model is reported in Table 4 . We begin our discussion with the impact of our control variables. The control variables generally have significant coefficients with signs as predicted. The median quantile regression model delivers significant coefficients on all covariates except for Population. The results with respect to the former indicate that there is no support for the hypothesis that teams with bigger local populations and hence market size pay higher salaries to running backs. ${ }^{13}$

Our discussion of the statistically significant control variables begins with experience. The turning point on Experience for the median regression is 6.8 years. With a typical drafting age from college of 21 or 22 , this corresponds to an age level that maximizes salary of 28 or 29 , a figure that is consistent with findings from other sports leagues (e.g. Lucifora and Simmons 2003 for Italian soccer).

As explained previously, NFL experience is preceded by the draft. Consistent with our expectation, the impact of being picked in round 2 of the draft is generally greater than for later rounds but less than for round $1 .{ }^{14}$ Veteran players gain a salary premium at the median and above. In the bottom half of the salary distribution, there is no

\footnotetext{
13 See Krautmann et al. (2007) for a similar result on NFL players generally. It could also be argued that smaller market locations (Green Bay and St. Louis for example) have fewer leisure substitutes. Chicago, New York, and San Francisco have more distractions and leisure options that compete with NFL games for audience attention.

14 Dummy variables for later rounds were never significant in alternative specifications. Our key results were unaffected by the inclusion of extra draft round dummy variables.
} 
premium. This suggests that free agency per se does not raise salary; free agency must be accompanied by requisite ability. Given sufficient ability, free agency clearly leads to higher salary, and this is indicative of monopsony power in the labor market for NFL players. At the median, the salaries rise as a player becomes a free agent by 38.2 per cent, provided that he stays with his original team. This could be argued to be an understatement of returns to free agency status as the experience variable will also reflect free agency. If a player achieves an extra year's playing experience, from four to five for full free agency, there is an additional salary increment of 9.0 per cent. If all of the extra experience reflects free agency, then this gives a total of 47.2 per cent premium to free agent status, at the median.

Restricted free agents earn a premium from the 0.25 quantile upward. The similarity of coefficient values of veteran and restricted free agent from median upwards suggests that franchises anticipate full free agent status of high ability players by rewarding them even after three years. Players who stay with their original team beyond free agency entitlement earn an additional premium compared to veterans who move.

In contrast, players who change teams suffer an immediate salary reduction. On the surface, this appears to be inconsistent with the existence of monopsony power. However, a better explanation can be couched in terms of asymmetric information and signaling. When a player becomes a free agent and his original team refuses to bid to retain his services, this signals that the original team believes that this player is overvalued in his present contract. Other teams may believe this, as the original team has superior information about player characteristics that are difficult to observe. ${ }^{15}$ Examples of these unobservable features are work ethic, temperament, off-field misdemeanors and lingering effects of prior injuries.

Beyond free agency, we find that players who gain Pro Bowl appearances receive increments to salary over and above performance and these are sustained for the full duration of their careers. In addition, fullbacks-who tend to block rather than run with or receive the ball-gain a salary premium as reward for their skills that are less well-observed (to the econometrician). This premium varies from 7.1 per cent at the 0.75 quantile to 11.4 per cent at the 0.10 quantile, although it is insignificantly different from zero at the 0.90 quantile.

The importance of blocking is not only seen with respect to fullbacks. Specifically, offensive line salary has significant coefficients at 10 per cent or better at all estimated quantiles. Overall, we interpret this as a strong indication of complementarity between the productivities of the offensive line and running backs. In essence, the quality of the offensive line blocking for a running back appears to affect his production and value. So far, the effects of complementarity of player inputs on player salaries have been under-researched (see Idson and Kahane 2000, for a notable exception).

Turning to the running back's production, we find that Career rush yards are a significant predictor of salary throughout the distribution (at 10 per cent significance or better). The significance of Career receiving yards, however, is not apparent at the 0.75 and 0.90 quantiles. Below these quantiles, the effect of 100 extra career receiving yards is significantly greater than the effect of 100 extra career rushing yards.

15 We are grateful to the special editor for suggesting this signaling interpretation of the adverse effect of changing team on player salary. 
To assess the effects of specialization on salary, we turn to our focus variables, Rush yards, Receiving yards, and Receiving yards * Rush yards. The coefficients on Rush yards and Receiving yards are significant and positive at all estimated quantiles. Moreover, the impacts are greater at quantiles above the median compared to below. ${ }^{16}$ The interaction term Receiving yards * Rush yards has a significant (at 10 per cent at least), negative coefficient at all estimated quantiles. Hence, the marginal salary returns to extra receiving yards declines with extra rush yards. Equivalently, the marginal salary returns to extra rushing yards declines with extra receiving yards. This is indicative of gains from specialization in either skill that is performed by NFL running backs.

Our results show that the marginal salary returns to one skill depend negatively on the performance level observed for the other skill. Although our results are statistically significant, it is important to also consider economic significance. Specifically, we wish to consider how the coefficients reported in Table 4 convert into predicted estimates of salary returns at different quantiles of the salary distribution.

Table 5 offers a simulation of these predicted returns, holding control variables and career rush and receiving yards constant. This permits a focus on the immediate impacts of 100 extra yards rushing or receiving. The values of rush yards and receiving yards shown in the table are taken from the salary distribution in the neighborhood of the specified quantile. The neighborhood is just above the preceding quintile and just below the next quantile to be estimated. Where positive, the estimated marginal returns are over and above the NFL league average salary increase for a particular season. Where negative, marginal salary returns are lower than the NFL league average, but do not necessarily imply salary reduction.

From Table 5, consider three running backs, each at the median of the salary distribution and each with the same control variable values (Experience, Offensive line salary, etc...). Additionally, each has the same value for career rush and receiving yards. Imagine, though, that we now observe differences with respect to Rush yards and Receiving yards. Running back A has become a rushing specialist with 1,000 rush yards from the previous season and zero receiving yards. His return to 100 extra rush yards is estimated as $6.60 \%$. His return to 100 extra receiving yards is $3.40 \%$. Running back B is now a receiving specialist with 1,000 pass reception yards in the previous season. His predicted marginal return to 100 extra receiving yards is $8.00 \%$. Running back $\mathrm{C}$ is multi-skilled; he runs with the ball and receives passes. Suppose his previous season performance levels are 500 yards in receiving and 500 yards rushing. The predicted marginal returns to 100 extra rush yards and 100 extra receiving yards are $4.30 \%$ and $5.70 \%$, respectively. For the multi-skilled player, therefore, there is little difference in marginal returns from extra performance in either skill, at the median. But the rewards to versatility are less than the rewards to specialization; running back C's marginal returns are dominated both by the larger returns to extra rush yards for the specialist rusher (6.60\% for A versus $4.30 \%$ for $\mathrm{C}$ ) and by the larger returns to extra receiving yards for the specialist pass receiver $(8.00 \%$ for B versus $5.70 \%$ for C).

16 The introduction of squared terms on Rush yards and Receiving yards delivered insignificant coefficients. A full translog specification of log salary is therefore unlikely to provide explanatory benefits. 
Table 5 Percentage returns to 100 extra rush yards or 100 extra pass yards

\begin{tabular}{|c|c|c|c|c|}
\hline Quantile & Pass yards & $\begin{array}{l}\text { Returns to } 100 \\
\text { extra rush yards at } \\
\text { different pass } \\
\text { yards }\end{array}$ & Rush yards & $\begin{array}{l}\text { Returns to } 100 \\
\text { extra pass yards at } \\
\text { different rush } \\
\text { yards }\end{array}$ \\
\hline \multirow[t]{4}{*}{$10 \%$} & 0 & 4.00 & 500 & 1.35 \\
\hline & 200 & 2.94 & 300 & 2.41 \\
\hline & 400 & 1.88 & 100 & 3.47 \\
\hline & 500 & 1.35 & 0 & 4.00 \\
\hline \multicolumn{5}{|l|}{ Median } \\
\hline \multirow[t]{2}{*}{ Player $^{a}{ }^{a}$} & 0 & 6.60 & 1000 & 3.40 \\
\hline & 200 & 5.68 & 800 & 4.32 \\
\hline \multirow[t]{2}{*}{ Player C } & 500 & 4.30 & 500 & 5.70 \\
\hline & 800 & 2.92 & 200 & 7.08 \\
\hline Player B & 1000 & 2.00 & 0 & 8.00 \\
\hline \multirow[t]{5}{*}{$90 \%$} & 0 & 8.40 & 1500 & -2.85 \\
\hline & 300 & 5.07 & 1200 & 0.48 \\
\hline & 700 & 0.63 & 800 & 4.92 \\
\hline & 1200 & -4.92 & 300 & 10.47 \\
\hline & 1500 & -8.25 & 0 & 13.80 \\
\hline
\end{tabular}

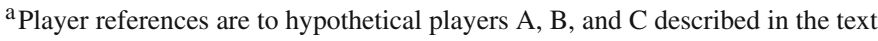

Moving up the salary distribution, we see greater disparities between marginal returns of the versatile players and the specialists. Consider the simulated returns at the 90th percentile in Table 5. A player that specializes in rushing with 1,500yards rushing and zero pass reception yards gains a predicted marginal salary return of $8.40 \%$ from 100 extra rush yards. However, if this player has 100 extra yards pass reception and no extra rush yards, the marginal salary return is $-8.25 \%$. A receiving specialist with 1,500 pass reception yards and zero rush yards in the previous season, derives a predicted return of $13.80 \%$ from 100 extra receiving yards but a much lower return, $-2.85 \%$, from 100 extra rush yards. A more versatile player with 800 yards rushing and 700 yards pass receptions would generate marginal returns of $0.63 \%$ from 100 extra rush yards and $4.92 \%$ from 100 extra receiving yards. At the 90 th percentile, it appears from our simulation that the marginal returns to specialists from extra performance levels in the specialized skill exceed the returns to versatile players from extra performance levels in either of their key skills. Similar disparities can be derived from a simulation of estimates of log salary at the 75 th percentile.

The difference in marginal returns between specialist and versatile players has widened at the top quantile of the salary distribution. Of course, this is partly due to the fact that expected performance levels are greater at higher quantiles of the salary distribution. Consequently this makes the downward impact of our interaction term larger for a given coefficient. But the coefficients on the interaction term are also greater in absolute magnitude at 75 th and 90 th percentiles compared to lower quantiles. These two effects combine to deliver the disparities in marginal returns shown in Table $5 .{ }^{17}$

17 The above comparison of marginal returns held constant the accumulated career totals of players. They should be viewed as one-shot returns. Career totals respond with a lag of one season. At median and below, the returns to extra career receiving yards exceed those from extra career rush yards. This ordering reverses 
Let us return to the specific cases of Barry Sanders and Marshall Faulk. Both players are in our data set. As noted in the introduction, Sanders can be regarded as a running specialist while Faulk is a more versatile player. Due to the scaling of nominal salary by NFL average wage, both players appear near (actually above) the 90th percentile of the salary distribution, even though Sanders exits our sample in 1998 while Faulk first appears in our sample in 1995.

Let us take starting values of rush yards and receiving yards to be 1,883 and 283, respectively, for Sanders (his 1995 values) and 1,381 and 1,048 for Faulk (his 2000 values). Our simulation at the 90th percentile shows returns to 100 extra yards rushing and receiving for Sanders to be $6.26 \%$ and $-6.32 \%$, respectively. In contrast, the comparable returns for Faulk are estimated as $-2.81 \%$ and $-0.10 \%$. The specialist has greater returns from his particular skill of rushing compared to the secondary skill of catching passes. Also, he generates greater returns to specialization compared to versatility. Even allowing for the full impact on career values, Faulk would still have a greater pecuniary incentive to develop a specialty with respect to pass receptions rather than maintain his capability with respect to both aspects of running back performance.

An example of a pass reception specialist in our sample is Chester Taylor. In 2005, he had 184 rush yards and 825 pass reception yards. According to our simulation, his marginal returns to 100 extra receiving and 100 extra rush yards, respectively, would have been $11.83 \%$ and $-0.43 \%$, suggesting an incentive for greater specialization in pass receptions.

The higher marginal returns to receiving yards over rush yards in the Table 5 simulation are consistent with the higher team returns to pass yards over rush yards that we found in section 2 above. Receiving yards have a larger impact on team outcomes, and this is reflected in both marginal revenue products of running backs with respect to the two performance indicators and differentials in salary returns.

\section{Conclusion}

In the NFL, we observe players - specifically, running backs-with well-defined tasks and precise performance measures. Our production function analysis reveals that running backs who gain pass reception yards generate higher productivity for their teams, as measured by offensive points, than do similar running backs who gain the same number of extra rushing yards. We were able to test for returns to specialization by distinguishing between returns to pass reception yards and returns to running yards. Total yards achieved in a season was found to be the most fundamental performance measure that drives player salaries.

\section{Footnote 17 continued}

at 75 th and 90th percentiles as returns to extra receiving yards become insignificantly different from zero. The apparent superior returns to receiving yards over rush yards in this part of the salary distribution is then partially offset by the delayed impact on career rush yards and then salary. The adjustment to the figures reported in Table 5 is small, however. At the 75 th percentile, the impact of 100 extra rush yards on salary through career rush yards is only $0.30 \%$; at the 90 th percentile the extra stimulus to salary from this source is $0.46 \%$. Hence, the additional of salary returns via career measures is rather small compared to the immediate impacts through prior season performance. 
Our analysis controls for a number of relevant covariates, including experience, draft position on entry to the NFL, free agent status, and reputation proxied by appearance in a Pro Bowl. We find substantial returns to acquisition of free agent status. Going beyond previous studies of major league salaries, we can control for team complementarity by using positional payroll as a proxy for quality of team units, in particular offensive linemen, who augment the performance and productivity of running backs. The significant estimated impacts of these covariates appear plausible. Returns to free agency are substantial and indicate the presence of monopsony power in the NFL player labor market. Moreover, the returns to free agent status are only realized if players remain with their original teams.

Our main finding is that there are pronounced gains to specialization for running backs, particularly at the top end of the salary distribution. We find that the marginal returns to receiving (rush) yards falls with extra rush (receiving) yards. The coefficient on the interaction term between receiving yards and rush yards is negative and significant at all estimated quantiles. When we simulate the model, we find substantial predicted differences in returns from receiving and rush yards as between specialists and versatile players. Again, these differences are more pronounced at the 75th and 90th percentiles. Specialization, rather than versatility, does appear to pay for NFL running backs.

\section{Data Appendix}

The sample used in the salary analysis comprises 1,425 player-seasons, over 1995 to 2006 inclusive, for running backs with at least one year's actual playing experiencei.e., rookies are excluded, and experience is defined as at least one play in the previous season. The definitions, measurement, and sources for variables in our analysis are as follows:

Log real salary: Log of total annual salary, inclusive of basic pay, signing bonus pro-rated over life of contract and other bonuses; deflated by average salary of all NFL players in a given season. Source: USA Today and Rod Fort's Sports Business web site.

Except where stated below, all measures were taken from NFL Record and Fact Book:

Experience: number of years experience as member of NFL team rosters, where rookies have the value 1 .

Draft round: dummy variables: one denotes a player selected in draft round 1 or 2 .

Veteran: dummy variable: one denotes player with more than four years experience.

Stayer: dummy variable: one denotes Veteran who has not changed team from prior season

Restricted free agent: dummy variable, one denotes a player with three years experience entitled to restricted free agent status.

Change team: dummy variable: one denotes a player who changed team from prior season.

Offensive line salary: log of total salary of offensive line of team of running back, deflated by average NFL wage. Source: USA Today and Rod Fort's Sport Business web site. 
Pro bowl: dummy variable: one denotes selection for Pro Bowl at any time prior to the present season. Source: ESPN.

Population: log of SMSA population in a given year. Source: Bureau of Economic Analysis.

Fullback: dummy variable: one denotes a fullback as designated by NFL Record and Fact Book.

Career rush yards: number of accumulated rush yards up to and including two seasons prior to the current season, measured in 10,000 yards. Source: Carroll et al. (1999) and NFL Record and Fact Book.

Career pass yards: number of accumulated pass reception yards up to and including two seasons prior to the current season, measured in 10,000 yards. These yards include additional rush yards after the football is received. Source: Carroll et al. (1999) and NFL Record and Fact Book

Rush yards: number of rush yards achieved in the previous season. Measured in units of 100 yards. Source: NFL Record and Fact Book.

Receiving yards: number of pass reception yards achieved in the previous season. Measured in units of 100 yards. Source: NFL Record and Fact Book.

Acknowledgements We are grateful to Lawrence Hadley for urging us to study specialization in the NFL. We also thank John Heywood, Kevin Quinn, participants at the Western Economic Association conference at San Diego, special issues editor Victor Tremblay, and three anonymous referees for helpful comments on an earlier draft.

\section{References}

Bardasi, E., \& Taylor, M. (2008). Marriage and wages: A test of the specialization hypothesis, Economica, 75, 569-591.

Baron, J., \& Kreps, D. (1999). Strategic human resources: Frameworks for general managers. New York: Wiley.

Berri, D. J. (2007). Back to back evaluation on the gridiron. In J. H. Albert \& R. H. Koning (Eds.), Statistical thinking in sport (pp. 235-256). Boca Raton: Chapman \& Hall/CRC.

Berri, D. J., Schmidt, M. B., \& Brook, S. L. (2006). The wages of wins. Stanford: Stanford Business Press.

Berri, D., Simmons, R. (2009). Race and the evaluation of signal callers in the National Football League. Journal of Sports Economics, 10, 23-43.

Black, S. E., \& Lynch, L. M. (2004). What's driving the new economy?: The benefits of workplace innovation. Economic Journal, 114, F97-F116.

Bodvarsson, O. B., \& Partridge, M. D. (2001). A supply and demand model of co-worker, employer and customer discrimination. Labour Economics, 8, 389-416.

Borland, J. (2006). Production functions for sporting teams. In W. Andreff \& S. Szymanski (Eds.), Handbook on the economics of sport (pp. 610-615). Cheltenham: Edward Elgar.

Carmichael, H. L., \& MacLeod, W. B. (1993). Multiskilling, technical change and the Japanese firm. Economic Journal, 103, 142-160.

Carroll, B., Gershman, M., Neft, D., \& Thorn, J. (1999). Total football II: The official encyclopedia of the National Football League. New York: Harper Collins.

Football Outsiders. Retrieved 24 April 2007 from http://www.footballoutsiders.com.

Garica-del-Barrio, P., \& Pujol, F. (2007). Hidden monopsony rents in winner-take-all markets: Sport and economic contributions of Spanish soccer players. Managerial and Decision Economics, 28, 57-70.

Garicano, L., \& Hubbard, T. N. (2007). Managerial leverage is limited by the extent of the market: Hierarchies, specialization and the utilization of lawyers' human capital. Journal of Law and Economics, 50, $1-43$. 
Green, F., Machin, S., \& Wilkinson, D. (1998). The meaning and determinants of skill shortages. Oxford Bulletin of Economics and Statistics, 60, 167-185.

Hamilton, B. H. (1997). Racial discrimination and professional basketball salaries in the 1990s. Applied Economics, 29, 287-296.

Hendricks, W., DeBrock, L., \& Koenker, R. (2003). Uncertainty, hiring and subsequent performance: The NFL draft. Journal of Labor Economics, 21, 857-886.

Ichniowski, C., \& Shaw, K. (2003). Beyond incentive pay: Insiders' estimates of the value of complementary human resource management practices. Journal of Economic Perspectives, 17, 155-180.

Idson, T. L., \& Kahane, L. H. (2000). Team effects on compensation: An application to salary determination in the National Hockey League. Economic Inquiry, 38, 345-357.

Kahn, L. M. (1992). The effects of race on professional footballers' compensation. Industrial and Labor Relations Review, 45, 295-310.

Kahn, L. M. (2000). Sports as a labor market laboratory. Journal of Economic Perspectives, 14, 75-94.

Kahn, L. M., \& Shah, M. (2005). Race, compensation and contract length in the NBA: 2001-2002. Industrial Relations, 44, 444-462.

Koenker, R. (2005). Quantile regression. Cambridge: Cambridge University Press.

Krautmann, A. (1999). What's wrong with Scully-estimates of a player's marginal revenue product? Economic Inquiry, 39, 599-608.

Krautmann, A., von Allmen, P., \& Berri, D. J. (2007). The underpayment of restricted players in North American sports leagues. Presented at Western Economic Association International Conference, Seattle.

Leeds, M., \& Kowalewski, S. (2001). Winner take all in the NFL: The effect of the salary cap and free agency on the compensation of skill position players. Journal of Sports Economics, 2, 244-256.

Lucifora, C., \& Simmons, R.(2003). Superstar effects in sport: Evidence from Italian soccer. Journal of Sports Economics, 4, 35-55.

Medoff, M. H. (1976). On monopsonistic exploitation in pro baseball. Quarterly Review of Economics and Business, 16, 113-121.

Quinn, K. G. (2006). Who should be drafted? Predicting future professional productivity of amateur players seeking to enter the National Football League. St.Norbert College, mimeo.

Raimondo, H. (1983). Free agents' impact on the labor market for baseball players. Journal of Labor Research, 4, 183-193.

Scully, G. W. (1974). Pay and performance in Major League Baseball. American Economic Review, 64, 915-930.

Simmons, R., \& Forrest, D. (2004). Buying success: Team performance and wage bills in U.S. and European sports leagues. In R. Fort \& J. Fizel (Eds.), International sports economics comparisons (pp. 123-140). Westport, CT: Praeger.

Stigler, G. J. (1951). The division of labor is limited by the extent of the market. Journal of Political Economy, 59, 185-193.

The NFL Record \& Fact Book. Various Editions. 